\title{
Origins of differences in hemoglobin concentration between Himalayan and Andean populations*
}

\author{
A. R. Frisancho \\ Center for Human Growth and Development, University of Michigan, Ann Arbor, MI 48109, U.S.A.
}

(Accepted for publication 21 November 1987)

\begin{abstract}
Mean hemoglobin concentration of 3511 adult males derived from 19 studies of Andean male permanent residents and 10 studies of Himalayan male permanent residents were compared with reference to partial pressure of inspired oxygen. The regression equation (weighted for sample size) of $\mathrm{PI}_{\mathrm{O}_{2}}$ and hemoglobin concentration of the Andean miners is significantly $(P<0.01)$ greater than that of the Andean and Himalayan non-miners. However, the relationship of $\mathrm{PI}_{\mathrm{O}_{2}}$ and $\mathrm{Hb}$ is similar in the non-mining Andean and Himalayan samples. These findings suggest that the observed differences in hemoglobin concentration between Andean and Himalayan samples are due, in part, to the inclusion of miners in the Andean samples. The higher barometric pressure associated with the north latitude location of the Himalayans may also contribute to decrease the hypoxic stress in the Himalayas. The present data suggest that Andeans and Himalayans have a similar hemopoetic response to hypoxic stress.
\end{abstract}

Altitude; Andes; Hemoglobin; Himalayas

The relationship between altitude and hemoglobin concentration has been wellestablished (Hurtado et al., 1945; Reynafarje, 1957). However, recent studies have indicated that the relationship of altitude and hemoglobin is less marked in the Himalayas than in the Andes (Morpurgo et al., 1979; Beall et al., 1983; Beall and Reichsman, 1984). These differences could be due to either variability in hypoxic stress or actual population differences. First, at the same altitude the hypoxic stress in the Himalayas is less than in the Andes. Various investigations have pointed out that because of its north latitude location the barometric pressures in the Himalayas at the same altitude are considerably higher than in the Andes (Haldane and Prieste, 1935; Pugh, 1957; West et al., 1983).

Second, the lower hemoglobins of the Himalayans could be related to the fact that some of the Andean subjects studied were residents of mining communities (Hurtado et al., 1945; Reynafarje, 1957; Cosio, 1973; Santolaya et al., 1981). Since miners are

\footnotetext{
* Dedicated to Professors Paul T. and Thelma S. Baker on the occasion of their retirement. Correspondence address: Dr. A. Roberto Frisancho, Center for Human Growth and Development, $300 \mathrm{~N}$. Ingalls, University of Michigan, Ann Arbor, MI 48109, U.S.A.
} 
known to suffer from a variety of chronic respiration disorders, including silicosis and chronic mountain sickness (Ruiz, 1973), which impairs oxygen transport, any evaluation of the role of hypoxia in hemoglobin response needs to take this factor into account (Frisancho, 1983; Garruto and Dutt, 1983). Therefore, there is a need to reevaluate the hemopoetic responses to altitude of Himalayan and Andean populations. Hence, with this purpose the relationship of partial pressure of oxygen in the inspired air $\left(\mathrm{PI}_{\mathrm{O}_{2}}\right)$ and hemoglobin concentration of Andean and Himalayans is compared through regression analysis.

\section{Method}

From the literature data were selected on hemoglobin concentration of 3511 males derived from 29 adult samples living permanently in the Andes and the Himalayas. The samples included only adult males living permanently at a given altitude, irrespective of ethnic admixture.

The Andean group included 19 sample means with a total of 3133 subjects belonging to Quechua, Aymara and Mestizo ethnic groups living in the Andes of Peru, Bolivia, and Chile (Hurtado et al., 1945; Reynafarje, 1957; Cosio, 1973; Ruiz, 1973; Frisancho et al., 1975; Chiodi, 1978; Arnaud et al., 1979; Santolaya et al., 1981; Winslow et al., 1981; Clench et al., 1982; Garruto and Dutt, 1983; Tufts et al., 1985). Based on the information given in each report, the Andean samples were classified as living in either mining or non-mining areas, irrespective of whether they actually worked as miners.

The Himalayan group included 10 sample means with a total of 378 subjects belonging to ethnic groups referred to as Tibetans, Sherpas, Tamills, and Ladakhis, living in the Himalayas (Pugh, 1966; Guleria et al., 1971; Bharadwaj et al., 1973; Adams and Shresta, 1974; Adams and Strong, 1975; Morpurgo et al., 1979; Samaja et al., 1979; Beall and Goldstein, 1987). The mean hemoglobins for male Phala Nomads between 4850 and $5450 \mathrm{~m}$ living in the Himalayas recently studied by Beall and associates (Beall and Goldstein, 1987) are also included here.

Since it is not high altitude that causes hypoxia but the associated low barometric pressure, we have analyzed the relationship of hemoglobin concentration to the partial pressure of inspired $\mathrm{O}_{2}$ rather than to altitude. Based on the altitude given in each report, the barometric pressures (Torr) in all studies were derived using the tables of International and Aviation Organization Standard Atmosphere (Manual of ICAO, 1968). The partial pressure of $\mathrm{O}_{2}$ in the inspired air $\left(\mathrm{PI}_{\mathrm{O}_{2}}\right)$ was calculated following standard procedures. The relationship of $\mathrm{PI}_{\mathrm{O}_{2}}$ and hemoglobin concentration was evaluated using regression analyses. Because of the variability in the sample size the regression equation of $\mathrm{PI}_{\mathrm{O}_{2}}$ on $\mathrm{Hb}$ was weighted for sample size differences.

\section{Results and Discussion}

Table 1 summarizes the data on hemoglobin concentration, altitude and inspired $\mathrm{P}_{\mathrm{O}_{2}}$ of the 29 samples. It is quite evident that at a given altitude or inspired $\mathrm{P}_{\mathrm{O}_{2}}$ the Andeans 


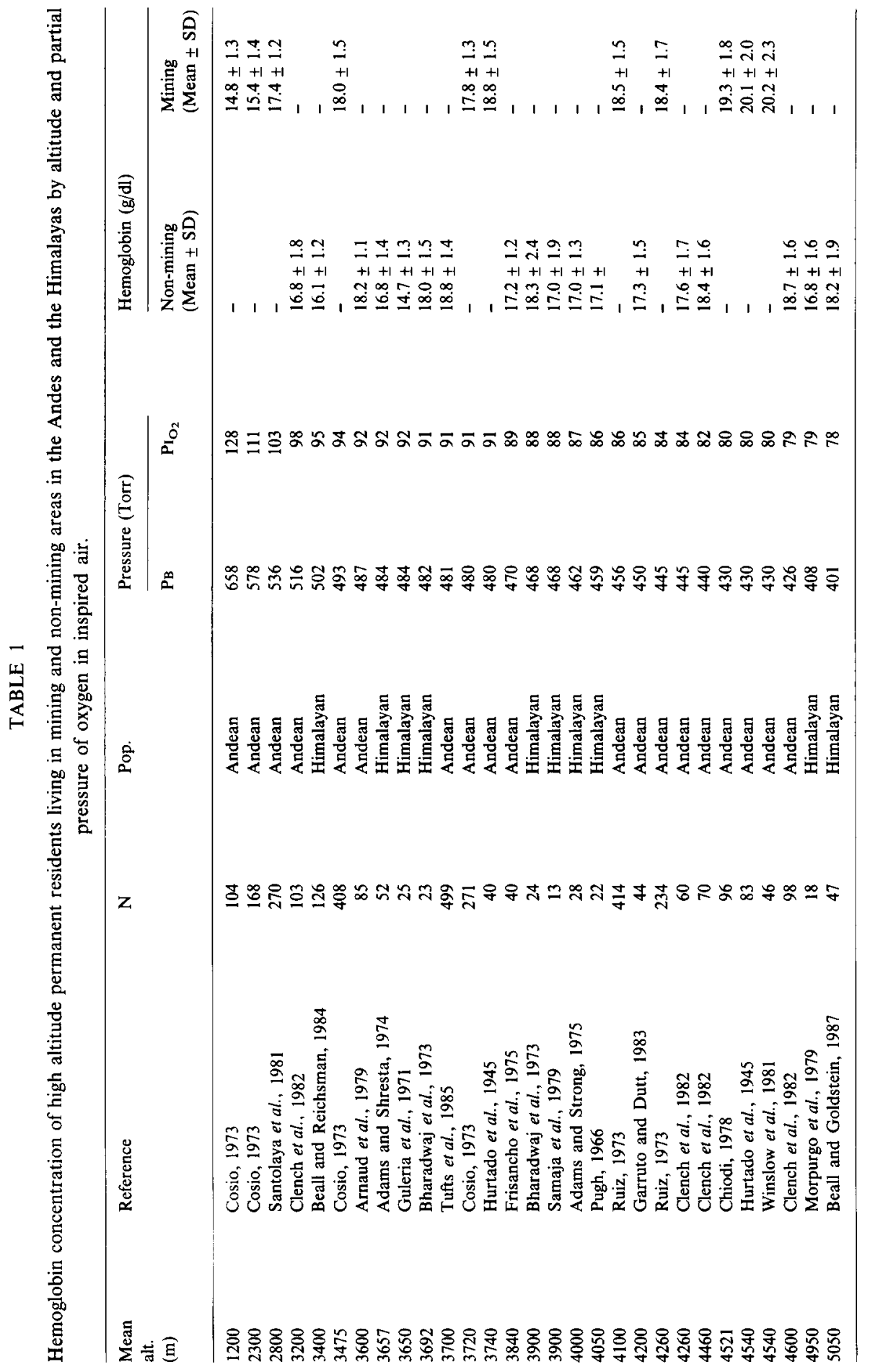


living in mining areas have significantly higher hemoglobin concentration than the Andeans not living in mining areas. As shown in fig. 1A the difference in hemoglobin concentration between those living in mining areas and those living in non-mining areas increases with altitude. In contrast, fig. 1B shows that Andeans not living in mining areas have a similar hemoglobin concentration to that of the Himalayans. These findings suggest that, contrary to previous assertions (Morpurgo et al., 1979; Beall et al., 1983; Beall and Reichsman, 1984), both Andeans and Himalayans have a similar hemopoetic response to hypoxic stress.

Since mining is associated with pollution, which in turn can accentuate hypoxia, the enhanced polycythemia of Andeans living in mining areas probably represents a response to the compound stress of mining and altitude. As previously indicated (Frisancho, 1981), from the point of view of functional adaptation high polycythemia represents either only a temporary response to hypoxia made by sea-level natives who are partially acclimatized to high altitude or an exaggerated response to the compound stress of pollution associated with mining and high altitude hypoxia. On the other hand,

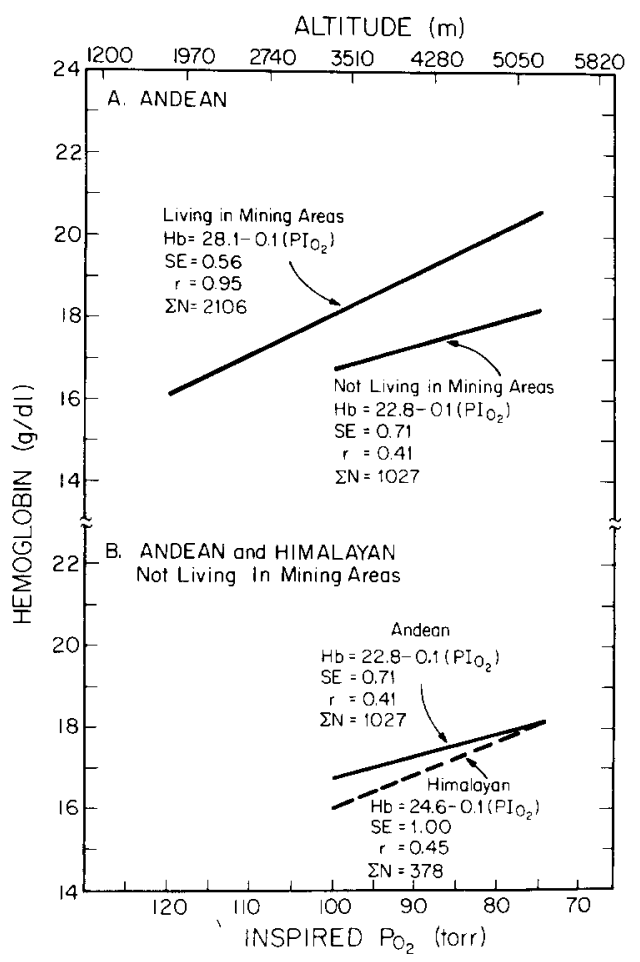

Fig. 1. Increase in hemoglobin concentration $(\mathrm{g} / \mathrm{dl})$ associated with a decrease in the partial pressure of inspired $\mathrm{O}_{2}\left(\mathrm{Pl}_{\mathrm{O}_{2}}\right)$. Note that among Andeans the increase in $\mathrm{Hb}$ is significantly greater in the samples living in mining areas than in those not living in mining areas. On the other hand, the increase in $\mathrm{Hb}$ is similar in both Andeans and Himalayans not living in mining areas. 
a complete functional adaptation like that exhibited by Andeans not living in mining areas and Himalayans requires only a moderate polycythemic response. This is because acclimatization to high altitude is attained not only through hemopoetic response but through physiological and morphological adaptations acquired during the developmental period.

Another factor which may contribute to lower the hemoglobin concentration of the Himalayans is that the barometric pressure because of its north latitude location is higher at the same altitude than in the Andes. Various investigations have pointed out that barometric pressures on mountains in the equatorial or temperate zones are considerably higher than those predicted from ICAO (Haldane and Prieste, 1935; Pugh, 1957; West et al., 1983). For example, Pugh (1957) reports that the barometric pressure reading for Mount Everest at $8888 \mathrm{~m}$ was 269 Torr, while the ICAO Standard Atmosphere table gives 236 Torr. This difference of 33 Torr units represents a height of $467 \mathrm{~m}$. The cause for the lower hypoxic stress in the Himalayas appears to be related to its north latitude location, which is associated with higher barometric pressure. As pointed out by West et al. (1983), the barometric pressure in the altitude range of 2 to $16 \mathrm{~km}$ bulges markedly near the equator. For this reason, and as a result of a combination of complex radiation and convective phenomena, the coldest air in the atmosphere is above the equator. Another effect of the bulge in barometric pressure is that the junction between the troposphere (where all the weather events take place), and the stratosphere (where the temperature of the air is essentially independent of altitude) is much higher near the equator than near the poles. Thus, the barometric pressure is higher (or a given altitude related to hypoxic stress is decreased) in the mountains situated above the equator or toward the poles, and lower (or the altitude related to hypoxic stress is increased) in the mountains situated below the equator. The fact that at a given altitude the barometric pressure is higher in the Himalayas indicates that at an equivalent altitude the Andeans are exposed to greater hypoxic stress than the Himalayans and therefore one would expect that hemoglobin be also higher in the Andeans than in the Himalayans.

\section{References}

Adams, W. H. and S.M. Shresta (1974). Hemoglobin levels, vitamin $B_{1} 2$ and folate status in a Himalayan village. Am. J. Clin. Nutr. 27: 217-219.

Adams, W.H. and L.J. Strong (1975). Hemoglobin levels in persons of Tibetan ancestry living at high altitudes. Proc. Soc. Exp. Biol. Med. 49: 1036-1039.

Arnaud, J., J. Quilici, N. Gutierrez and J. Beard (1979). Methaemoglobin and erythrocyte reducing systems in high-altitude natives. Ann. Hum. Biol. 6: 585-593.

Beall, C.M., K.P. Strohl and B.M. Gary (1983). Reappraisal of Andean high altitude erythrocytosis from a Himalayan perspective. Semin. Respir. Med. 5: 195-201.

Beall, C.M. and A.B. Reichsman (1984). Hemoglobin levels in a Himalayan high altitude population. $A m$. J. Phys. Anthropol. 63: 301-306.

Beall, C.M. and M.C. Goldstein (1987). Hemoglobin concentration of pastoral nomads permanently resident at 4850-5450 $\mathrm{m}$ in Tibet. Am. J. Phys. Anthropol. 73: 433-438.

Bharadwaj, H., A. Singh and S. Malholya (1973). Body composition of the high altitude natives of Ladakh. A comparison with sea-level residents. Hum. Biol. 45: 423-434. 
Chiodi, H. (1978). Aging and high-altitude polycythemia. J. Appl. Physiol. 45: 1019-1020.

Clench, R., E. Ferrell and W.J. Schull (1982). Effect of chronic altitude hypoxia on hematologic and glycolytic parameters. Am. Phys. Soc. 447-451.

Cosio, G. (1973). Hematic and cardiopulmonary characteristics of the Andean miner. Bol. Of. Sanit. Panam. English Edition VII: 26-33.

Frisancho, A. R., T. Velasquez and J. Sanchez (1975). Possible adaptive significance of small body size in the attainment of aerobic capacity among high-altitude Quechua natives. In: Biosocial Interrelations in Population Adaptation, edited by E. Watts, F.E. Johnston and G. W. Lasker. The Hague, Morton, pp. 55-64.

Frisancho, A.R. (1981). Human Adaptation: A Functional Interpretation, 2nd edition. Ann Arbor, University of Michigan Press.

Frisancho, A.R. (1983). Perspectives on functional adaptation of the high altitude native. In: Hypoxia, Exercise, and Altitude: Proceedings of the Third Banff International Hypoxia Symposium, edited by J.R. Sutton, C. S. Houston and N.L. Jones. New York, Alan R. Liss, pp. 383-401.

Garruto, R.M. and J.S. Dutt (1983). Lack of prominent compensatory polycythemia in traditional nature Andeans living at 4200 meters. Am. J. Phys. Anthropol. 61: 355-366.

Guleria, J.S., J.N. Pande, P. K. Sethi and S.B. Roy (1971). Pulmonary diffusing capacity at high altitude. J. Appl. Physiol. 31: 536-543.

Haldane, J. S. and J.G. Priestley (1935). Respiration, 2nd edition. New Haven, Yale University Press.

Hurtado, A., C. F. Merino and D. Delgado (1945). Influence of anoxemia on the hemopoietic activity. Arch. Intern. Med. 75: 284-323.

Manual of the ICAO Standard Atmosphere (1968). International Civil Aviation Organization. Montreal, 2nd edition.

Monge, M.C. and C.C. Monge (1966). High-Altitude Diseases. Springfield, C.C. Thomas.

Morpurgo, G., P. Battaglia, N. D. Carter, G. Modiano and S. Passi (1979). The Bohr effect and the red cell 2-3 DPG and $\mathrm{Hb}$ content in Sherpas and Europeans at low and high altitude. Experientia 28: 1280-1283.

Pugh, L.G.C. (1957). Resting ventilation and alveolar air on Mount Everest: with remarks on the relation of barometric pressure to altitude in mountains. J. Physiol. (London) 135: 590-610.

Pugh, L. G.C. (1966). A programme of physiological studies of high-altitude peoples. In: The Biology of Human Adaptability, edited by P.T. Baker and J.S. Weiner. Oxford, Clarendon Press.

Reynafarje, C. (1957). The influence of high altitude on erythropoietic activity. Brookhaven Symp. Biol. 10: $132-146$.

Ruiz, L. (1973). Epidemiologia de la hipertension arterial y de la Cardipatia isquemica en las grandes alturas: Prevalencia y factores relevantes a su historia natural. Doctoral Thesis Universidad Peruana Cayetano Heredia.

Samaja, M., A. Veicsteinas and P. Cerretelli (1979). Oxygen affinity of blood in altitude Sherpas. J. Appl. Physiol. 47: 337-341.

Santolaya, R., J. Araya, R. Vecchiola, R. Prieto, R. M. Ramirez and R. Alcayaga (1981). Hematocrito, hemoglobina y presion de oxigeno arterial en 270 hombres y 26 mujeres sanas residentes de altura (2.800 mts.) Rev. Hosp. Roy H. Glover 1: 17-29.

Tufts, D. A., J.D. Haas, J.L. Bear and H. Speivogel (1985). Distribution of hemoglobin and functional consequences of anemia in adult males at high altitude. Am. J. Clin. Nutr. 42: 1-11.

West, J. B., S. Lahiri, K.H. Maret, R.M. Peters and C.J. Pizzo (1983). Barometric pressures at extreme altitudes on Mt. Everest: physiological significance. J. Appl. Physiol. 54: 1188-1194.

Winslow, R. M., C. C. Comge, N. J. Statham, C. G. Gibson, S. Charache, J. Whittenbury, O. Moran and R. L. Berger (1981). Variability of oxygen affinity of blood: human subjects native to high altitude. J. Appl. Physiol. 61: 1411-1416. 